\title{
Flow structure diagnostics in a four-vortex furnace model using PIV-method
}

\author{
Evgeniy Shadrin ${ }^{1, *}$, Anatoliy Papulov ${ }^{1,2}$ \\ ${ }^{1}$ Institute of Thermophysics SB RAS, Novosibirsk, Russia \\ ${ }^{2}$ Novosibirsk State University, Novosibirsk, Russia
}

\begin{abstract}
In this paper the flow structure in a four-vortex furnace of a pulverized coal boiler has been studied. The results of an experimental study of inner aerodynamics carried out on a laboratory isothermal model of a combustion device are presented. Using the particle image velocimetry method, flow velocity distributions have been obtained in a number of sections. A spatial flow structure consisting of four stable conjugate vortices with vertical flow rotation axes has been visualized.
\end{abstract}

The perspectives of coal energy development necessitate the creation of new ways of efficient and environmentally safe use of solid fuels. The limited reserves of high-quality solid fuels lead to the need to involve low-grade ("non-project") coals in the fuel and energy balance. The solution of this problem requires a significant increase in the characteristics of steam boilers of TPPs and the development of new types of combustion devices that satisfy modern standards of energy efficiency and environmental safety. One of the promising technologies in this field is fuel combustion in the vortex flow. The flow swirling provides for a more complete fuel burnup due to better mixing and longer residence time of fuel particles in the combustion chamber.

In this paper, the flow structure in a perspective combustion device [1] with a fourvortex solid fuel combustion scheme is experimentally studied. Four vortical structures with vertical axes and opposite directions of rotation are formed there. The furnace is designed for the use at thermal power plants for burning brown slagging coal. The furnace is equipped with a shielded rectangular combustion chamber. Two diagonally directed blocks of multilevel burners are mounted on the sidewalls; they are close to the axis of symmetry of the sidewalls so that the ratio of distance between the burners to the burner height is $0.8-1.2$. In the center of the front and rear walls, there are nozzles of secondary and tertiary inflow, made in the form of vertical near-wall slots, whose height is equal to the height of the burner unit and oriented relative to each other in opposite directions along the walls, where they are located. Primary fuel combustion occurs in the direct-flow part of the side burner flame. Due to optimal positioning of the side burners, efficient interaction of burner jets mixing and ignition is achieved via intensive flue gas suction in the inter-burner space. The colliding straight-flow parts of the flame, directed from the sidewalls towards each other, turbulize the flow, and due to the nozzles of secondary and tertiary inflow, form four vortex flows with vertical rotation axes (Fig. 1-a).

*Corresponding author: evgen zavita@mail.ru 
The four-vortex scheme of pulverized coal combustion [1] was developed for boiler BKZ-320-140, station No. 18 at Krasnoyarsk CHP-1 with its transfer from liquid to dry slag removal. It was also implemented at reconstructing furnaces of boilers BKZ-640-140TP at the Gusinoozerskaya TPP (Russia). According to the practice, burning the high-ash coals in the furnaces of BKZ boilers leads to intense slagging of the furnace and steam superheaters, whereby the boiler load is reduced. Evaluating the effectiveness of boiler reconstruction has identified a number of shortcomings in boiler operation, requiring its further modernization. To improve the technical, economic and environmental performance, it is necessary to optimize operating and design parameters of the four-vortex furnace of the pulverized-coal boiler on the basis of a detailed study of its aerodynamics on laboratory models.

To study the flow structure in the four-vortex furnace model, an experimental stand was developed and debugged. The scheme of this stand is shown in Fig. 1-b. The main elements of this stand are [2]: compressed air supply system with control and regulating devices; four-vortex furnace model; system for seeding a stream by tracer-particles; and measuring system.

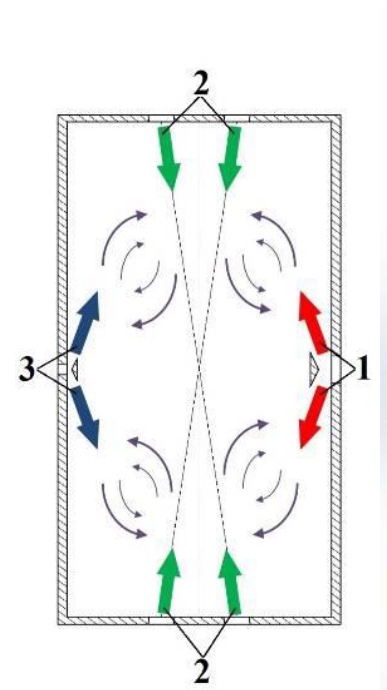

a)

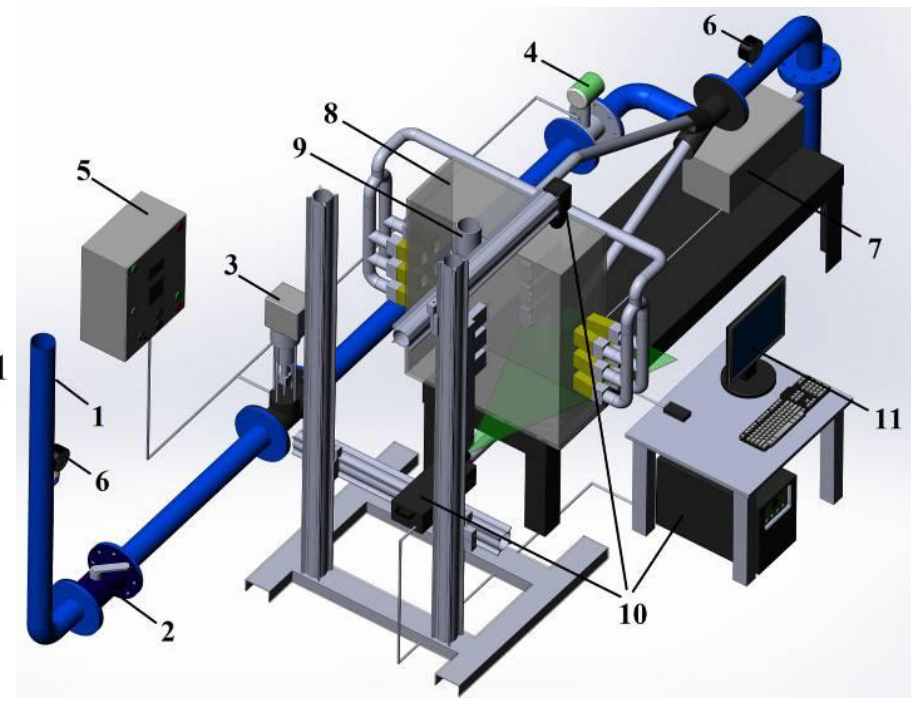

b)

Fig.1. Four-vortex fuel combustion scheme (a): 1 - dust-air mixture flow through the front nozzles; 2 - dust-air mixture flow through the side nozzles; 3 - tertiary air; (b): 1 - compressed air supply line, 2 - stop valve, 3 - flow control valve, 4 - flow meter, 5 - control box, 6 - manometers, 7 - fog generator, 8 - four-vortex furnace model, 9 - ventilation, 10 - PIV measuring system, 11 - computer.

The model is made of $10 \mathrm{~mm}$ thick plexiglass at a scale of 1:25 (internal dimensions $290 \times 880 \times 730 \mathrm{~mm}$ ). On the side walls at three levels, there are two diagonally directed nozzles at an angle of $6^{\circ}$ (dimensions $28 \times 50 \mathrm{~mm}$ ), and the axes of the side nozzles are directed to the center of the furnace. On the front and rear walls at three levels (locations of side nozzles are marked), there are also two central nozzles (dimensions of front nozzles $23 \times 66 \mathrm{~mm}$, and rear ones $-11 \times 64 \mathrm{~mm}$ ) directed towards the side walls at an angle of $20^{\circ}$.

Study of the flow structure in the four-vortex furnace model was carried out using the particle image velocimetry (PIV) method, which is the more productive in comparison with the method of laser Doppler anemometry, also used for diagnostics of flow pattern [3-7]. 
PIV is a non-contact optical panoramic method, allowing measurements with high performance. Measurements of the instantaneous flow velocity field in a given section are based on the measurement of the motion of impurity particles (tracers) located in the plane of the section under study, for a fixed time interval. This displacement is determined based on the application of correlation methods to tracer pictures, using regular partitioning into elementary cells.

In this work the PIV-system "POLIS" (development of IT SB RAS) was used; it consists of the CCD camera Videoscan 4021 (with a resolution $2048 \times 2048$ pixels, the frequency of shooting up to $1.25 \mathrm{~Hz}$, and an exposure time of $28 \mathrm{~ms}$ ) and a pulsed $\mathrm{Nd}$ : YAG laser QuantelEVG (wavelength of $532 \mathrm{~nm}$, energy in the pulse up to $145 \mathrm{~mJ}$, and a pulse duration of $10 \mathrm{~ns}$ ). To obtain the average velocity field, a series of 100 pairs of images was conducted in each measuring section. The regime under which the velocity was 5 and $3 \mathrm{~m} / \mathrm{s}$ in the outlet from the side and central nozzles, respectively, was investigated. In horizontal sections, the flow is symmetrical with respect to the vertical plane passing through the center of the central walls of the furnace. Therefore, in order to increase the spatial resolution and save the time of the experiment, measurements were made only in the half area of the investigated horizontal cross-sections (290 x $365 \mathrm{~mm})$.

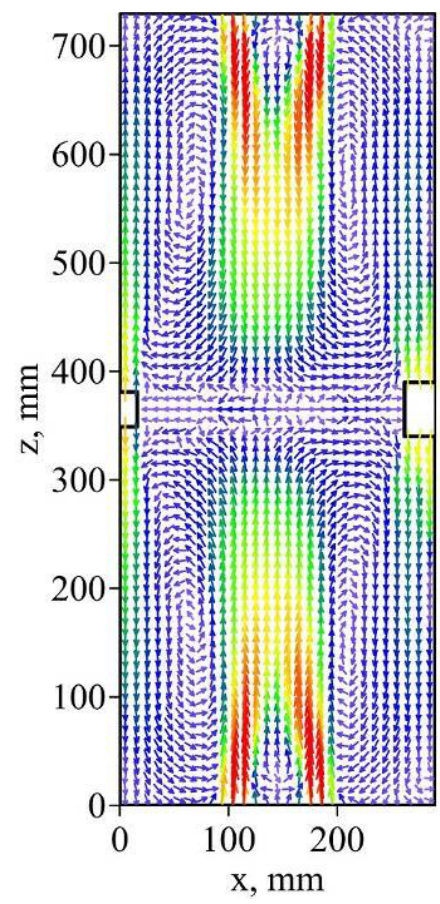

(a)

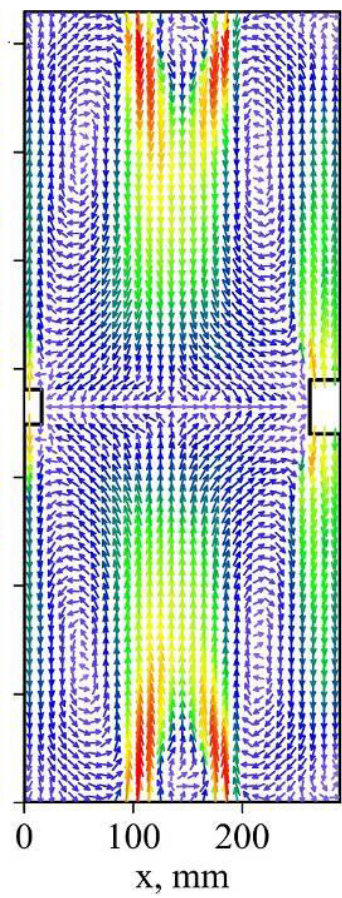

(б)

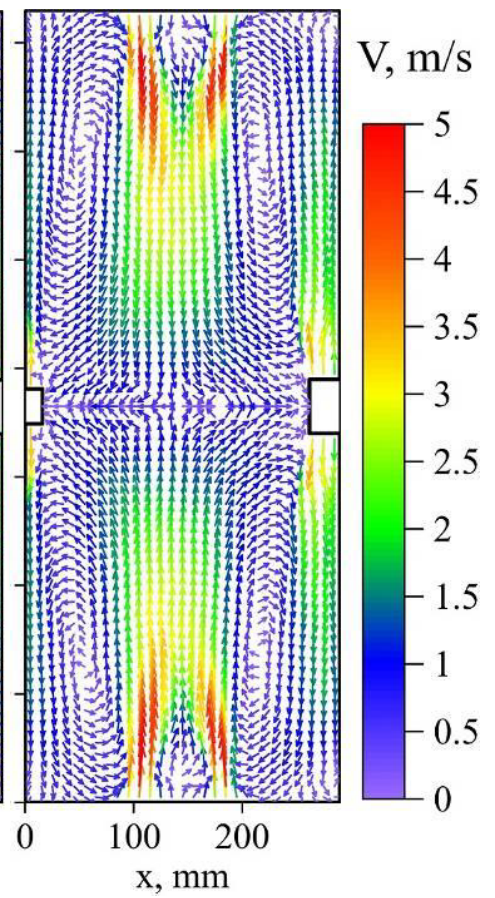

(в)

Fig.2. The time-average flow velocity field in a four-vortex furnace model in horizontal sections at the marks of the centers of three levels of nozzles (in the figures the spatial grid spacing is $1 \mathrm{~cm}$ ): (a) the lower level; (b) the middle level; (c) the upper level.

The obtained results show the complex structure of the flow in the investigated furnace model, consisting of four conjugate stable vortices. The jets, which flow from the nozzles located on the side walls at a distance of three nozzle calibers, merge and spread as a single stream to the center of the furnace. Then the stream turns back and, interacting with the jets which flow from the central nozzles, is directed parallel to the front and rear walls. In the 
corners, the stream turns and flows to the bottom of the side burners, thereby forming four closed vortices with vertical axes and opposite direction of rotation.

With this flow structure, there is an intensive "washing" of the furnace screens (maximum tangential velocity is near the walls), which in practice contributes to the improvement of convective heat transfer. With such an aerodynamic scheme, a long torch length is provided; there is no direct surge of the unburned fuel particles on the screens, which reduces the danger of intense surface slag typical for the frontal arrangement of the burners. The mounting of tertiary blast nozzles is a necessary condition for the formation of a four-vortex flow structure and, at the same time, allows organizing a gradual combustion of fuel in order to reduce emissions of nitrogen oxides.

The results of the research are useful for verification of developing mathematical models applied in full-scale numerical simulations of furnace processes $[8,9]$.

The study was carried out with the financial support of the Russian Science Foundation (project No. 14-29-00093).

\section{References}

1. S.V. Sryvkov, M.Ya. Protsailo, A.A. Dekterev, S.G. Kozlov, M.S. Pronin, A.M Kovalevsky, V.P. Popov, RF Patent No. 2032853 (1995) [in Russian]

2. I.S. Anufriev, D.O. Glushkov, A.P. Papulov, E.Yu. Shadrin, MATEC Web of Conf. 92, 01059 (2017).

3. I.S. Anufriev, O.V. Sharypov, E.Yu. Shadrin, Tech. Phys. Lett. 39466 (2013)

4. Yu.A. Anikin, I.S. Anufriev, E.Yu. Shadrin, O.V. Sharypov, Thermophys. Aeromech. 21, 807 (2014)

5. I.S. Anufriev, D.V. Krasinsky, E.Yu. Shadrin, O.V. Sharypov, Tech. Phys. Lett. 40, 879 (2014)

6. I.S. Anufriev, P.A. Strizhak, M.Yu. Chernetskii, E.Yu. Shadrin, O.V. Sharypov Tech. Phys. Lett. 41, 727 (2015)

7. I.S. Anufriev, P.A. Kuibin, E.Yu. Shadrin, D.K. Sharaborin, O.V. Sharypov, Thermophys. Aeromech. 23, 621 (2016)

8. M.Yu. Chernetskiy, V.A. Kuznetsov, A.A. Dekterev, N.A. Abaimov, A.F. Ryzhkov Thermophys. Aeromech. 23, 591 (2016)

9. D.V. Krasinsky, O.V. Sharypov, J. Eng. Thermophys. 24, 348 (2015) 